\title{
Evaluation of Self-leadership Statue and Providing Solutions to Improve the Self-leadership Statue (Payam Noor University- Kermanshah Branch Case Study)
}

\author{
Ameneh Malmir ${ }^{1}$ and Fariba Azizzadeh ${ }^{2}$ \\ ${ }^{1}$ Department of management Esfahan, Science and Research Branch, Islamic Azad \\ University, Iran \\ amenehmalmirlyahoo.com \\ ${ }^{2}$ Department of management Esfahan, Science and Research Branch, Islamic Azad \\ University, Iran (Correspondence) \\ Sazizzadeh2010@yahoo.com
}

\begin{abstract}
Leadership is an essence, which through this essence series of intellectual and humanistic abilities and capabilities could be mixed and by managing and controlling this essence organization goals could be achieved in a better and effective way. Management in the organization is not too much difficult, but staying in the leadership position is difficult task. Leadership to the deep phase of the organization is not something happens immediately, but must be established in schematized process in the organization.

Team leadership basic principle in the organization is self-leadership, and this is because that team selfleadership is the organization leadership practice. Self leadership is self-knowing, self-awareness, selfmanage and self-discipline, that each one of these components helps the leadership to run and implement its effects on the organization. The goal of the present paper is to analyze self-leadership component and their relationship with Payam-Noor university Kermanshah branch personnel's psychological capabilities. This study is applicative in term of goals perspective, and is statistical in term of implementation perspective. All the personnel of Payam Noor university-Kermanshah branch in 2011-2012 were chosen as the statistical society, that were 220 persons and the sample size was selected to be consist of 140 persons. Material and methods: A self-leadership questionnaire with 18 questions and reliability coefficient of $70 \%$ was used as a tool to collect the data. The data analysis on inferential level was conducted with T-test and the research finding show that there is significant correlation between self leadership components of Payam Noor University personnel.
\end{abstract}

\section{KEYWORDS}

Leadership, Self-leadership Component, Self-management, University Personnel

\section{1- INTRODUCTION}

Technology progress and advancement particularly quick communication, being without boundaries and limit (independency), data recovery and sharing the knowledge could be referred as the challenges the organizations are facing in 21 century. Changes are inevitable and must be planned and managed to cause constructive and effective changes in the organizations. Modern world, increasingly, needs this kind of leadership that values the establishment of organizations, which moves toward activating their potencies and yet, think of solving the crisis and emergency situation at the work place. Modern work-force consist of trained persons that expect more from 
their profession and their number is increasing and since vast amount of information is available 21 century work force frequently is called as the "knowledge-base work force." Knowledge-based

work force requires independency and power to make decision and quick action. They do not look for someone else guidance and management. In fact command- control style of leadership is replacing with involving the personnel, empowering them and work-groups self- management. Command- control style of leadership is not compatible with organizations that focus on the use of the innovation and creativity as a tool for saving the competition-made benefits.

Many researchers confirmed the need of a new style of leadership which is compatible with these changes. Self- leadership and its strategies, with emphasis on becoming a more effective person could meet the challenges facing the organizations which seek innovation and creativity in 21 century.

In this study, which is conducted as an analytical- descriptive study, self leadership components are introduced and discussed.

\section{Literature Review}

\subsection{Self-leadership Components}

To lead others, one must lead his own self (Himself). In defining leadership as process of influencing others, Charles Manz exhibited that self- leadership could be considered as influence on our own "self". This influencing behavior is explainable as learning behavior and is placed in the heart of the leadership development. Three areas that self-leadership is manifested are as: 1self-awareness of personal values 2- intentions and behavior 3- personal perspective.

1- Self-awareness of personal values: knowing that, who and how we want to be, has significant importance, but knowing who we are, have decisive and definite role. Self-awareness of values, intentions, strength and weaknesses points are considered the internal leadership principles. Commitment to self-awareness shows the desire of being in active position (situation which person does not stop in face of challenges), i.e. a certain person, who does not possess the answers and is considered as a learner. Self-awareness through feedback: Morgan Mac call said: lack of awareness, whether, because of ignorance or arrogant, is considered an important factor in persons deviance.

Leadership development depends, not only to self-awareness and our understanding, but also to our desire to be influenced by others. Other people evaluation of our defects (imperfection) and moving toward changing our behavioral attitudes has significant importance. Paying attention to our critics and supporters is the first step toward self-awareness. Moreover to our positive qualities, awareness of our own inconsistency, bias, and subjective ignorance helps our knowledge to enhance our leadership behaviors.

To do so, feedback could be received formally and informally, frequently feedback comes from the supervisor immediately, but we can receive useful information from those who work with us every day. Some organizations make, use of many raters and feedback receiver of 360-degree and obtain official and rich feedback of personnel's, observe the actions and behaviors.

This survey is compromised with the individual self- concept from other's respondent perspectives, Regardless of the way used to receive feedback and despite that it must be various.

The work key is the adoption of a proactive approach instead of passive approach in order to receive feedback. There is no substitute for the multidimensional attitude to the behavior and its effect on other person and the organizations.

2- Building a personal perspective: self-leadership foundation is what a person wants to be or achieve. Exactly as organizations which lack a clear perspective, persons also could be the same 
International Journal of Managing Public Sector Information and Communication Technologies (IJMPICT)

Vol. 4, No. 1, March 2013

and without guiding and clear perspective runs their energies in the wrong way. Personal perspective development requires consuming time to think about our desire.

3- Learning in term of environmental (work-place) awareness importance: self awareness and personal perspective happens in one field. As far as the skills are developing, self-leaders are aware of what the organizations and their professions expect from them on the same time. Profound understanding and active participation in our own professional- related life will cause instantaneous force and targeted goal to be created and without it, development as self-leadership will not be meaningful. Understanding of the workplace which professionally is in progress and finding the required competencies for being superior involve asking, studying, and above all communication with those who unusually we do not communicate normally. While we have accustomed to learn from our close limits, we must learn from remote communication. These could be personnel and groups, which, seemingly are away from close field and colleague circle or could be the members of industry personnel's which are in competition. These communications have the potency of widening the organizations body of knowledge and saving us from falling into innate short sightedness (parochialism).

4- Self-management: self-management is one of self-leadership components. In order to manage for your own, you must practice in various aspects [37].

Leadership can organize from the self and does not require the traditional roles of leader and follower. Instead they can be one in the same, as leadership is self-imposed. Self-leadership posits that all organizational members are capable of leading themselves. Traditional leadership is grounded in external influence and control exercised [23]. Self-leadership means that individuals will receive their motivation and control from their inner self. There would be nothing morally right or wrong if people would not feel emotions of social approval or disapproval. Selfleadership related to those traits that could provide social approval for leaders' decisions and actions. Self-leadership strategies enhance the perception of self-efficacy [14].

\subsection{All Kind of Leadership}

Leadership definition: some experts believes leadership is part of management duties and other group of experts consider wider meaning and definition for leadership in comparison with management and defines it as the potency to encourage others to try eagerly in order to achieve certain goals or consider them activities which influence persons to try eagerly to achieve the group goals. Competent leaders involve employees towards the efforts of achieving organizational excellence. They do this by using their:

- Cognitive skills (ability to see things in many different ways, and self-knowledge ability to understand and manage oneself)

- Emotional resilience (ability to maintain confidence and objectivity under difficult circumstances)

- Personal drive (determination to succeed, to be proactive, and to take personal risks) [13]. 
Key success factors for leaders:

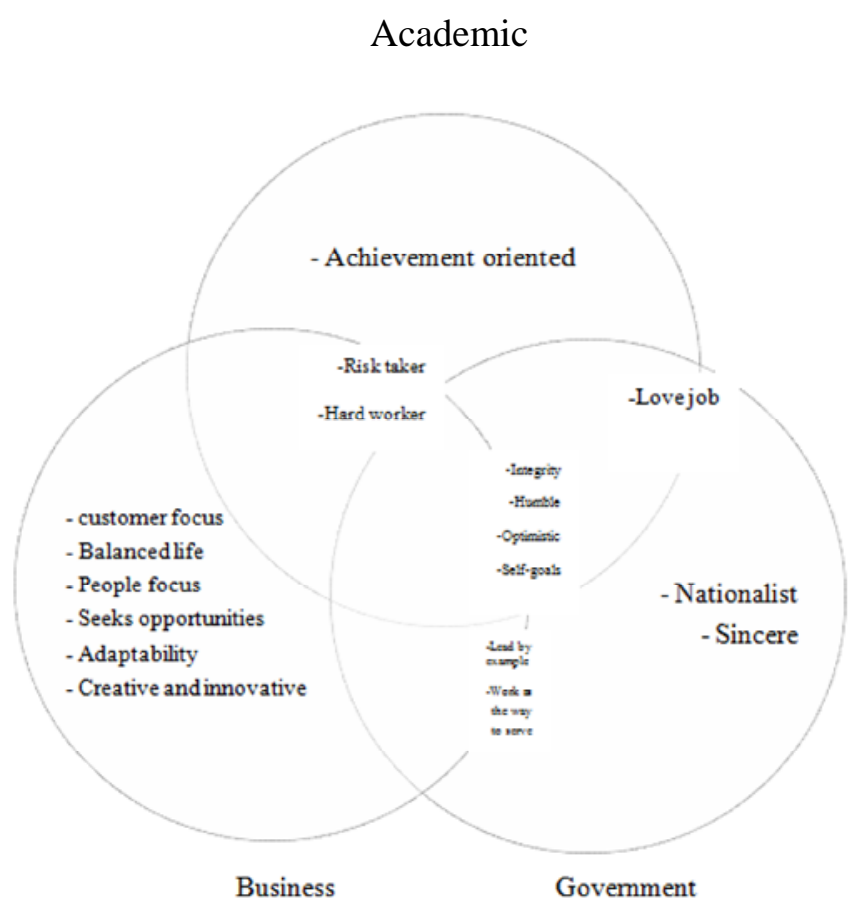

Figure1. Common success factors for academic-business-government leaders [33].

Leadership needs the management of social relationships. Leaders use social capital through the acuity with which perceive social structures and the actions. They build connections with important constituencies within and across social divides [8]. Leadership style acts as a facilitator and stimulator of the direct and indirect effects on people's creativity [28]. Also in order to lead, people must acquire and polish leadership skills, especially communication and stress management [4]. The researches show that the females qualitatively involve the democratic style of leadership than the men. The democratic style of leadership involves consultation with other staff and a general involvement of all in the processes of decision-making [29]. As for leadership style, the democratic leadership is preferred than other types of leadership [44].

Innovation leadership profile of competencies is captured in figure 2 .

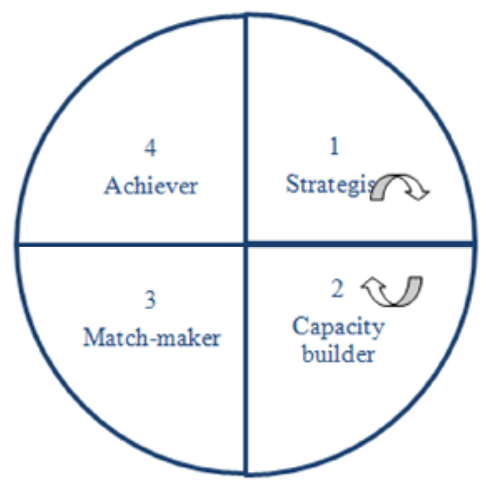

Figure2. Innovation leadership competency profile [41] 
International Journal of Managing Public Sector Information and Communication Technologies (IJMPICT) Vol. 4, No. 1, March 2013

Organizational behavior provides various style of leadership, that effective leadership, transformational leadership, servant leadership, charismatic leadership, strategic leadership and knowledgeable (sage, conversant) leadership could be named for example.

\subsubsection{Effective Leadership}

Effective leaders are able to deliver the vision of the way the followers of emotional persuasive and clear them believe in them. They can motivate followers to perform the work themselves and give the powers in decision-making [36]. Effective and dynamic leadership require three different skills:

- Diagnostic skills: i.e. ability to recognize the condition that tries to influence it.

- Matching skills: i.e. ability to match behavior and resource to deal with unexpected events.

- Communication skills: i.e. ability to communicate in such a way that person could understand and accept easily [30].

\subsubsection{Transformational Leadership}

Transformational leadership is the process of aware influence on people or groups to make discontinues change and evolution in the present condition or the organization performance as a whole. Transformational leadership lead the society to be developed by their words and behaviors, and have profound influence on their followers, this kind of leadership accomplish, when the leader apply their followers interest to the work, inform them about the goals and the missions (duties), and encourage them to think beyond their personal advantage. This kind of leadership is accomplished based on ideal influence, psychological encouragement, inspirational motivation and personal consideration [34].

Leadership style of senior managers in collective security organization is compatible with transformational leadership style. Increasing the transformational leadership factors in the organizations, the level of satisfaction, leader effectiveness and employees extra effort will increase [2]. Findings show that transformational leadership in Iranian car manufacturing organizations are higher than average [27]. The types of leadership have a strong relationship with organizational outcomes (efficiency, satisfaction and extra effort) [12]. Transformational leadership is associated with higher performance. People tend to use more transformational leadership [21]. This leadership style is positively related to safety climate in coal mine and it may play an important role in promoting safety leadership [43]. Transformational leadership views technological change as needing a combination of technical and human relations aspects. The largest barrier to "change" is not changes to technologies but changes involving people [18]. Transformational leadership can more broadly and deeply contribute to an organization's success. These leadership issues tend to arise most acuity when company's leaders come under severe scrutiny during times of business scandals and ethical crises [7, 22].

Leaders of petroleum sector follow transformational leadership style to manage their organization. The relationship between transformational leadership style and job satisfaction is positive significant relationship [10]. Transformational leaders need alongside authentic leaders because debate is often encouraged by them [3].

\subsubsection{Servant Leadership}

Robert green leaf introduced "servant leadership" among management modern theorist for the first time and in 1987 established the "servant leadership" concept. According to green leaf, "leaders first must pay attention to other persons needs." Moreover to Green Leaf other writers considered servant leadership a valid and modern theory in tem of organization leadershipservant leadership vales the human equality and seek the organization members' personal 
development [11]. These servants develop others through modeling attractive behaviors. The servant leader's behaviors contribute to the social learning of followers [7, 24].

\subsubsection{Gate-keeping Leadership}

Gate-keeping leadership is defined as an individual's ability to frequently engage in both internal and external communication. Gate-keepers can conduct intra-team communication by acquiring technical information through external communication. External communication promotes the acquiring information about manufacturing processes or consumer needs. Gate-keeping leadership encourages team members to display leadership [20].

\subsubsection{Strategic Leadership}

Strategic leadership is the process to influence on the desirable perspective of success that is used by the leaders and is accomplished with influencing on the organizational culture, resource allocation, guidance through policy, and agreement on the ambiguous, complex, uncertain and volatile global environment (work-place related) that is characterized with opportunities and challenges. This kind of leadership involve kind of strategic decision-making that is achieved by considering all the desire, personal differences, plans, organizations stake holders and different culture. Plans which these leaders schematize must be practical and should be pleasant and acceptable for the organization stakeholders, agents and national and international partners [32]. The strategic leadership effects strategic change and innovation in the detection of environmental uncertainty [5].

\subsubsection{Ethical Leadership}

Sustainable organization is one that recognizes that it has a purpose outside of business itself [16]. Ethical leadership is leader's personality and upbringing which involved five groups of leader social responsibility; moral-legal standard of conduct, internal obligation, concern for others, concern about consequences, and self-judgment. Morality and fairness, open communication with followers, trustworthy and honest, power sharing, and ethical role clarification are components of ethical leadership [7, 45]. Technical, conceptual, interpersonal skills along with emotional and social intelligence contribute to proper understanding of ethical values. Leaders enriched with these skills can show the way towards enhanced ethics oriented [19]. The ethics of leadership continue to attract public and scholarly attention [9]. Ethics are concerned with not only what should be, but with what should not be. Ethics means going beyond the requirements of the law and what may be profitable for the organization [26]. Ethical leadership is positively related to transformational culture. In fact Transformational leadership and transformational culture predict ethical leadership [38]. Also ethical leadership is positively related to follower organizational citizenship behavior and negatively related to deviance. These relations are moderated by followers' self-stem [6].

There is a differences and negative relation between the ethical leadership perceptions and strategic leadership perceptions. Decision-making is considered as the requirement of both ethical leadership and strategic leadership. Strategic leadership acts with profit impetus, but ethical leadership notices the universal values like justice, equality, honesty, impartiality, responsibility, respect, love, democracy, tolerance in their activities [40].

\subsubsection{Charismatic Leadership}

Charismatic leadership based on exceptional leadership refers to kind of leadership which the leaders possess the power and the ability to inspire the followers, while these abilities merely originate from the person power of personality and commitment. In this kind of leadership, relationships are built by leaders that have profound and extraordinary influence on their followers by using their personal ability, but not with financial rewards and coercion [7]. Intense 
sensitivity to the needs of team members is crucial for charismatic leadership [1]. Charismatic leadership is mainly communicative [15].

\subsubsection{Innovative Leadership}

Innovative leadership means introducing something new (idea, method, technique, process, product, service and etc) to solve current problems and satisfy employee's needs at the present and in the future. Innovative leaders have features in common, such as leadership knowledge, skills, vales, and talents to anticipate the negative impacts of problems on the future. They can solve current problems with a focus on the future [35].

\subsubsection{Inspirational Leadership}

Inspirational leadership or visionary leadership is one kind of leadership approach that has specific process for its own. Visionary leadership is human-related process that offers a perspective of the goals and orientation by the evolution factor influence in dealing with the needs. Process of ideal setting is constant and dynamic and must be considered as part of the leadership current duties. Ideals develop through series of processes. According to Westely and Mitzenberg, three certain components along a perspective are:

- Defining an image of the desired future for the organization

- Schematizing these visions

- Empowering the followers by transmitting the vision [30].

Empowering leadership provides meaning to workers' rule compliance in responding to complex and complicated problems [25].

\subsubsection{Global Leadership}

Leadership is increasingly confronted with problems of cultural heterogeneity outcome variables along various levels of analysis on future business challenges that companies will face due to the globalization process. Leadership as a lever to handle these globalization challenges [42]. The culture is the most important platform that the roots of the global leadership behaviors. Global leaders must have enough knowledge on national and international cultures. They must internalize the national and organization culture [46]. The globalization process and the nature of competition have been challenging organizations. The impacts of globalization on leadership involve:

- Learning behavioral dimensions required by different cultures

- Farsightedness

- Being proactive

- Managing disputes with cooperation

- Leading multicultural teams

\subsubsection{Virtual Organization's Leadership}

Virtual organizations have emerged seeing that the world has become extremely complicated compound and technological. Virtual organization's leadership should converge all of team elements because of the lack of sound communication among members. Applying appropriate leading strategies for virtual condition will not only raise the value of organizational productivity but also positively influence on the quality of trust and culture of members. Virtual organization's leadership require following skills:

1. Building cordial relationship with others

2. Scattering information and knowledge between members 
International Journal of Managing Public Sector Information and Communication Technologies (IJMPICT) Vol. 4, No. 1, March 2013

3. Convergence among members and objectives

4. Being honest with members

5. Setting face-to-face meeting as possible as for members [17].

Virtual world can be used to develop and enhance leadership skills [39].

From within above paradigms, there is acknowledgment of the fact that the interaction between leaders and their followers are of paramount importance [31].

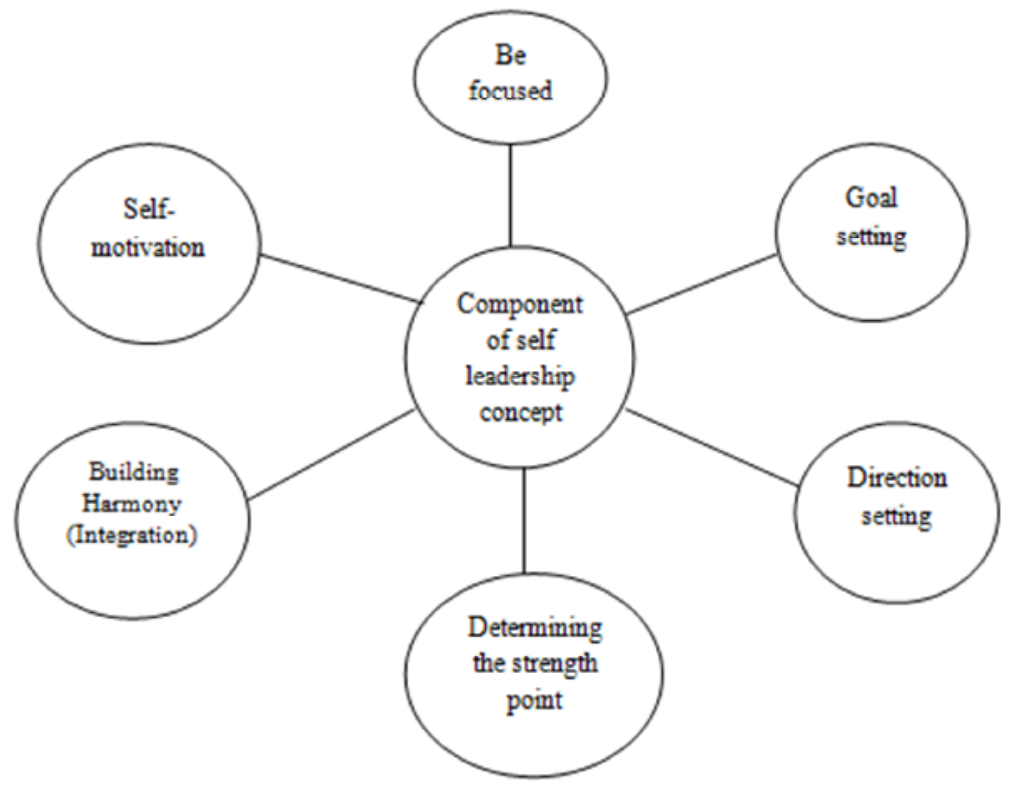

Figure3. Components of self leadership concept [37].

\section{RESEARCH HYPOTHESIS}

Main hypothesis: Payam Noor university personnel self-leadership is in ideal condition.

Alternative hypothesis:

1. Payam Noor university personnel act successfully in be focused characteristic.

2. Payam Noor university personnel act successfully in goals setting characteristic.

3. Payam Noor university personnel act successfully in direction setting characteristic.

4. Payam Noor university personnel act successfully in determining strength point characteristic.

5. Payam Noor university personnel act successfully in building harmony (integration) characteristic.

6. Payam Noor university personnel act successfully in self-motivation characteristic.

\section{METHODS AND MATERIALS}

This research is descriptive-statistical study (descriptive survey). The statistical society was all the personnel of Payam Noor University, Kermanshah branch. The sample size was selected 140 
persons and questionnaires were used as a tool to collect the data. The questionnaires were composed of two parts that the first part was related to the customer's general characteristic as: age, sex, education, job level and the second part was, consist of questions about the hypothesis testing. The research validity was measured by management experts and professor's consultation to authenticate the questionnaires reliability and this study validity is $70 \%$. And as far as cronbach's Alpha is (0.816) the questionnaire has acceptable validity. Data analysis was conducted by using inferential and descriptive statistics and SPSS software. Standard deviation, mean and frequency were tested by using descriptive statistics and the theories were tested with ttest method by using inferential statistics, that the result are exhibited in the tables below.

\section{RESEARCH FINDINGS}

According to table 1 self-leadership mean and standard deviation of Payam Noor university personnel in term of effective indices are 11 and 71, respectively.

Table1. Main hypothesis descriptive statistics

\begin{tabular}{|l|l|l|l|}
\hline Raw & Main hypothesis & Mean & $\begin{array}{l}\text { Standard } \\
\text { deviation }\end{array}$ \\
\hline 1 & $\begin{array}{l}\text { Payam Noor university personnel self-leadership is in ideal } \\
\text { condition }\end{array}$ & 10.22 & 3.63 \\
\hline
\end{tabular}

Table2. Alternative hypothesis descriptive statistics

\begin{tabular}{|l|l|l|l|}
\hline Raw & alternative hypothesis & Mean & $\begin{array}{l}\text { Standard } \\
\text { deviation }\end{array}$ \\
\hline 1 & $\begin{array}{l}\text { Payam Noor university personnel act successfully in be } \\
\text { focused characteristic. }\end{array}$ & 9.75 & 3.44 \\
\hline 2 & $\begin{array}{l}\text { Payam Noor university personnel act successfully in goals } \\
\text { setting characteristic. }\end{array}$ & 10.86 & 3.86 \\
\hline 3 & $\begin{array}{l}\text { Payam Noor university personnel act successfully in } \\
\text { direction setting characteristic. }\end{array}$ & 10.25 & 3.65 \\
\hline 4 & $\begin{array}{l}\text { Payam Noor university personnel act successfully in } \\
\text { determining strength point characteristic. }\end{array}$ & 10.08 & 3.589 \\
\hline 5 & $\begin{array}{l}\text { Payam Noor university personnel act successfully in building } \\
\text { harmony (integration) characteristic. }\end{array}$ & 10.07 & 3.585 \\
\hline 6 & $\begin{array}{l}\text { Payam Noor university personnel act successfully in self- } \\
\text { motivation characteristic. }\end{array}$ & 10.31 & 3.67 \\
\hline
\end{tabular}

According to table 2 goal setting has the highest and be focused has the lowest mean. 
International Journal of Managing Public Sector Information and Communication Technologies (IJMPICT) Vol. 4, No. 1, March 2013

\subsection{Hypothesis Testing}

Testing Main hypothesis 1: main hypothesis in this study is:" Payam Noor university personnel self-leadership is in ideal condition" the following statistical theory is schematized in order to test the above hypothesis.

Payam Noor university personnel self-leadership is not in ideal condition: $\mathrm{H}_{0}$

Payam Noor university personnel self-leadership is in ideal condition: $\mathrm{H}_{1}$

The results comes from the questionnaires statistical data analysis are exhibited in the following table by using t-test (mean comparison test) in order to test the above hypothesis.

Table3. T-test results

\begin{tabular}{|l|l|l|l|l|}
\hline t-score & Freedom level & Error level & p-value & Test result \\
\hline 2.62 & 139 & $\% 5$ & $\% 0$ & $\mathrm{H}_{0}$ rejected \\
\hline
\end{tabular}

As it is exhibited in table 3 with level of confidence of $\% 95$, if the P-value is lower than error level of $\% 5, \mathrm{H}_{0}$ will be rejected and $\mathrm{H}_{1}$ is accepted. With regard to that $\mathrm{t}$-score is larger than $\mathrm{t}-$ table (1.71), so $\mathrm{H}_{0}$ hypothesis is rejected and $\mathrm{H}_{1}$ hypothesis is accepted, to state the matter differently, with confidence level of \%95 it could be said that self-leadership of Payam-Noor university personnel is in ideal condition, i.e. it could be said that the sample data has the required implication to accept $\mathrm{H}_{1}$.

Alternative hypothesis 1: Payam Noor university personnel act successfully in be focused characteristic.

$\mathrm{H}_{0-1}$ : Payam Noor University personnel do not act successfully in be focused characteristic

$\mathrm{H}_{1-1}$ : Payam Noor University personnel act successfully in be focused characteristic

Table4. Alternative hypothesis 1 testing results

\begin{tabular}{|l|l|l|l|l|}
\hline t-score & Freedom level & Error level & p-value & Test result \\
\hline 2.62 & 139 & $\% 5$ & $\% 0$ & $\mathrm{H}_{0-1}$ rejected \\
\hline
\end{tabular}

According to table 4 as far as the $\mathrm{t}$-score is higher than the $\mathrm{t}$ in the table (1.71), so the $\mathrm{H}_{0-1}$ hypothesis is rejected an $\mathrm{H}_{1-1}$ hypothesis is accepted, i.e. with confidence level of \%95 Payam Noor university personnel act successfully in be focused characteristic.

Alternative hypothesis 2: Payam Noor university personnel act successfully in goal setting characteristic.

$\mathrm{H}_{0-2}$ : Payam Noor University personnel do not act successfully in goal setting characteristic

$\mathrm{H}_{1-2}$ : Payam Noor University personnel act successfully in goal setting characteristic

Table5. Alternative theory 2 testing results

\begin{tabular}{|l|l|l|l|l|}
\hline t-score & Freedom level & Error level & p-value & Test result \\
\hline 2.92 & 139 & $\% 5$ & $\% 0$ & $\begin{array}{l}\mathrm{H}_{0-2} \\
\text { rejected }\end{array}$ \\
\hline
\end{tabular}


International Journal of Managing Public Sector Information and Communication Technologies (IJMPICT) Vol. 4, No. 1, March 2013

According to table 5 as far as the $t$-score is higher than the $t$ in the table (1.71), so the $\mathrm{H}_{0-2}$ hypothesis is rejected an $\mathrm{H}_{1-2}$ hypothesis is accepted, i.e. with confidence level of \%95 Payam Noor university personnel act successfully in goal setting characteristic.

Alternative hypothesis 3: Payam Noor university personnel act successfully in direction setting characteristic.

$\mathrm{H}_{0-3}$ : Payam Noor University personnel do not act successfully in direction setting characteristic

$\mathrm{H}_{1-3}$ : Payam Noor University personnel act successfully in goal direction characteristic

Table6. Alternative theory 3 testing results

\begin{tabular}{|l|l|l|l|l|}
\hline t-score & Freedom level & Error level & p-value & Test result \\
\hline 2.76 & 139 & $\% 5$ & $\% 0$ & $\begin{array}{l}\mathrm{H}_{0-3} \\
\text { rejected }\end{array}$ \\
\hline
\end{tabular}

According to table 6 as far as the t-score is higher than the $\mathrm{t}$ in the table (1.71), so the $\mathrm{H}_{0-3}$ hypothesis is rejected an $\mathrm{H}_{1-3}$ hypothesis is accepted, i.e. with confidence level of \%95 Payam Noor university personnel act successfully in direction setting characteristic.

Alternative hypothesis 4: Payam Noor university personnel act successfully in determining strength points characteristic.

$\mathrm{H}_{0-4:}$ Payam Noor University personnel do not act successfully in determining strength points characteristic

$\mathrm{H}_{1-4}$ : Payam Noor University personnel act successfully in determining strength points characteristic

Table7. Alternative hypothesis 4 testing results

\begin{tabular}{|l|l|l|l|l|}
\hline t-score & Freedom level & Error level & p-value & Test result \\
\hline 2.71 & 139 & $\% 5$ & $\% 0$ & $\begin{array}{l}\mathrm{H}_{0-4} \\
\text { rejected }\end{array}$ \\
\hline
\end{tabular}

According to table 6 as far as the t-score is higher than the $\mathrm{t}$ in the table (1.71), so the $\mathrm{H}_{0-4}$ hypothesis is rejected an $\mathrm{H}_{1-4}$ hypothesis is accepted, i.e. with confidence level of \%95 Payam Noor university personnel act successfully in determining strength points characteristic.

Alternative hypothesis 5: Payam Noor university personnel act successfully in building integration characteristic.

$\mathrm{H}_{0-5}$ : Payam Noor University personnel do not act successfully in building integration characteristic

$\mathrm{H}_{1-5}$ : Payam Noor University personnel act successfully in building integration characteristic

Table8. Alternative theory 5 testing results

\begin{tabular}{|l|l|l|l|l|}
\hline t-score & Freedom level & Error level & p-value & Test result \\
\hline 2.71 & 139 & $\% 5$ & $\% 0$ & $\mathrm{H}_{0-5}$ rejected \\
\hline
\end{tabular}


International Journal of Managing Public Sector Information and Communication Technologies (IJMPICT) Vol. 4, No. 1, March 2013

According to table 6 as far as the t-score is higher than the $t$ in the table (1.71), so the $\mathrm{H}_{0-5}$ hypothesis is rejected an $\mathrm{H}_{1-5}$ hypothesis is accepted, i.e. with confidence level of \%95 Payam Noor university personnel act successfully in building integration characteristic.

Alternative hypothesis 6: Payam Noor university personnel act successfully in self motivation characteristic.

$\mathrm{H}_{0-6}:$ Payam Noor University personnel do not act successfully in self motivation characteristic

$\mathrm{H}_{1-6}$ : Payam Noor University personnel act successfully in self motivation characteristic

Table9. Alternative hypothesis 6 testing results

\begin{tabular}{|l|l|l|l|l|}
\hline t-score & Freedom level & Error level & p-value & Test result \\
\hline 2.77 & 139 & $\% 5$ & $\% 0$ & $\begin{array}{l}\mathrm{H}_{0-6} \\
\text { rejected }\end{array}$ \\
\hline
\end{tabular}

According to table 6 as far as the $\mathrm{t}$-score is higher than the $\mathrm{t}$ in the table (1.71), so the $\mathrm{H}_{0-6}$ hypothesis is rejected an $\mathrm{H}_{1-6}$ hypothesis is accepted, i.e. with confidence level of \%95 Payam Noor university personnel act successfully in self motivation characteristic.

Table10. Mean of components

\begin{tabular}{|l|l|l|l|l|l|l|l|l|}
\hline $\begin{array}{l}\text { Compon } \\
\text { ents }\end{array}$ & $\begin{array}{l}\text { Number } \\
\text { s }\end{array}$ & $\begin{array}{l}\text { Be } \\
\text { focused }\end{array}$ & $\begin{array}{l}\text { goal } \\
\text { setting }\end{array}$ & $\begin{array}{l}\text { Direction } \\
\text { setting }\end{array}$ & $\begin{array}{l}\text { Determining } \\
\text { strength } \\
\text { points }\end{array}$ & $\begin{array}{l}\text { Building } \\
\text { integration }\end{array}$ & $\begin{array}{l}\text { Self } \\
\text { motivati } \\
\text { on }\end{array}$ & Total \\
\hline $\begin{array}{l}\text { Mab level } \\
\text { sanager }\end{array}$ & 20 & 11.00 & 12.33 & 11.00 & 10.33 & 11.66 & 11.66 & 11.33 \\
\hline Experts & 50 & 10.12 & 10.75 & 10.75 & 11.00 & 9.50 & 11.25 & 10.56 \\
\hline $\begin{array}{l}\text { Employe } \\
\text { es }\end{array}$ & 70 & 8.14 & 9.50 & 9.00 & 8.92 & 9.07 & 8.00 & 8.77 \\
\hline total & 140 & 9.75 & 10.86 & 10.25 & 10.08 & 10.07 & 10.31 & 10.22 \\
\hline
\end{tabular}

Approaches to improve self-leadership in Payam Noor university-Kermanshah branch:

According to the research results Payam Noor university personnel achieved the lowest score in being focused characteristic that its components are as follow:

- Emotion control

- Clarifying what is important

- Awareness of our own power

And the highest level was achieved in goal setting characteristic that its components are as following:

- Finding the problem to solve, troubleshooting

- Clarifying the goals

- Taking the responsibility of our behavior consequence

The following approaches are suggested to improve Payam Noor university personnel selfleadership 
1. Organizational authorities must be vouch safety clearly and without ambiguity, to provide the required ground for empowering self-leadership.

2.Building suggestion system is one of other required ground for utilizing the tool for empowering self-leadership that must be implemented effectively in the organization.

3. Working-groups must be prevalent in the organization as an important factor, reinforcing the process of self-leadership empowerment.

4.Personnel must be participated effectively in the process of goal setting to establish the process of self leadership empowerment.

5. Reward system must be based on the individual performances and competencies to move toward improving self-leadership empowerment.

6. Granting resources, training, budget and etc. to the personnel is of self-leadership process success preferences and in case of mistake occurrence, they will be ignored.

\section{CONCLUSIONS}

Self leadership is self-knowing, self-awareness, self-manage and self-discipline, that each one of these components helps the leadership to run and implement its effects on the organization. The goal of the present paper is to analyze self-leadership component and their relationship with Payam-Noor university Kermanshah branch personnel's psychological capabilities. Selfleadership is the main principle of forming organizational leadership and this is because that building the grounds and foundation of self-leadership in personnel will cause leadership to be manifested. Self-leadership is formed through influence on our own and become evolved with behavior and personal perspective and become applicative by self-management.

Self leadership leaders usually can lead their self and others better. One of leaders duty is that, train the organization personnel to be self-leader for to lead the organization to be self-leader after them. In this paper the main theory is as follow:

"Payam Noor university personnel self-leadership is in ideal condition" that the results came out of the research confirm this theory. Goal setting has the highest and be focused has the lowest mean. According to table 10 managers has the highest level of self leadership in comparison to the experts and employees, the total score of university personnel was 59/96 that is a good score and show that personnel make use of many of self-leadership skills and with practice Payam Noor personnel self-leadership will be perfect. In fact the research finding shows that there is significant correlation between self leadership components of Payam Noor University personnel. 


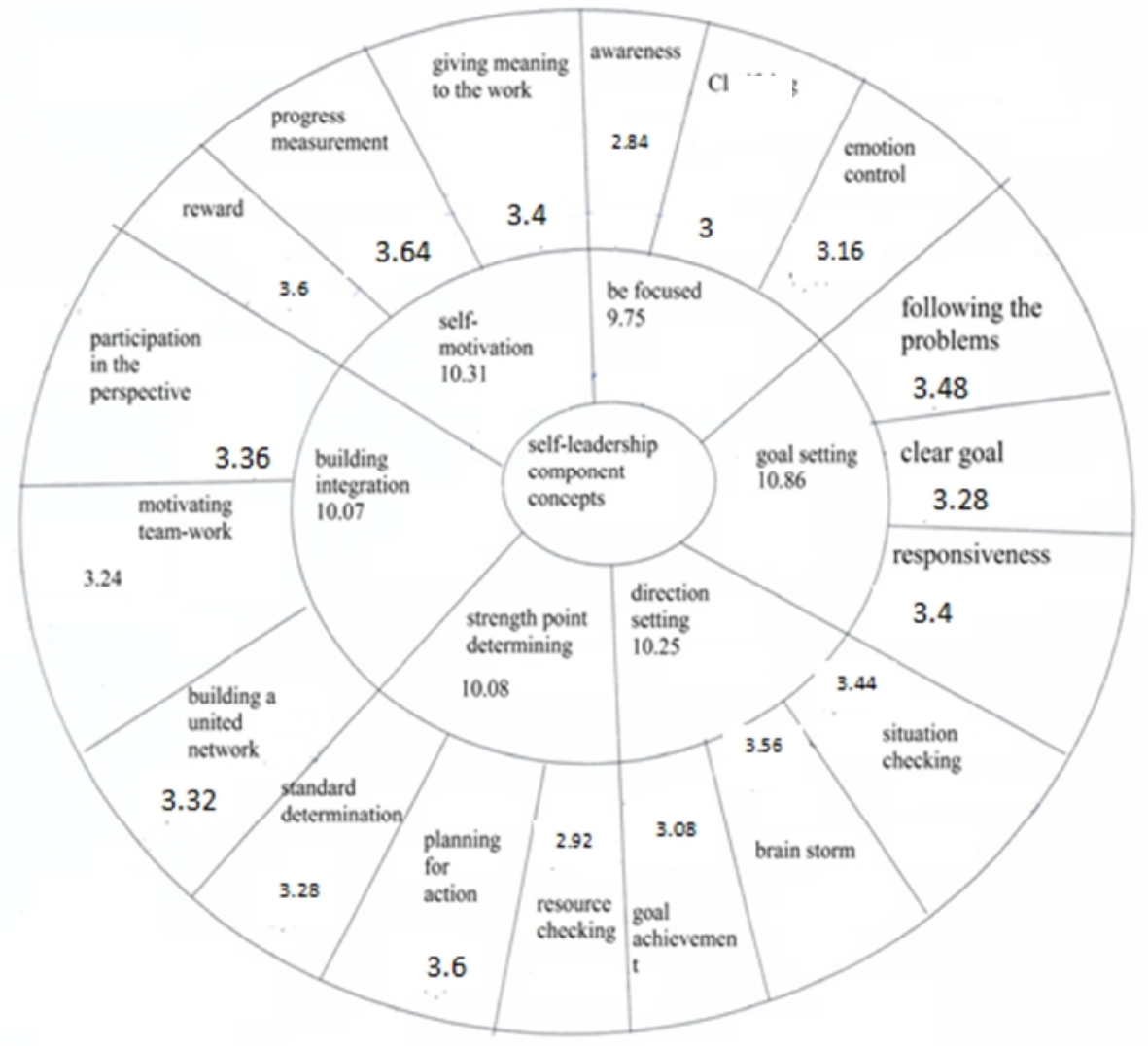

Figure4. The research hypothesis results

\section{REFERENCES}

1. Afacan Findikli, Mine \& Yozgat, Ugur, (2012) "A qualitative analysis of charismatic leadership in creative teams: the case study of Turkish TV series directors", Procedia-Social and Behavioral Sciences, Vol. 41, pp 227-236.

2. Allameh, Seyyed Mohsen \& Davoodi, Seyyed Mohammad Reza, (2011), "Considering transformational leadership model in branches of Tehran social security organization", Procedia Social and Behavioral Sciences, Vol. 15, pp 3131-3137.

3. Angus-Leppan, Tamsin \& Metcaff, Louise \& Ben, Sue, (2010) "Leadership Styles and CSR Practice: An Examination of Sensemaking, Institutional Drivers and CSR Leadership", Journal of Business Ethics, Vol. 93, pp 189-213.

4. Arif, Seema, (2011) "Broken Wings: Issues Faced by Female Doctors in Pakistan Regarding Career Development, International Journal of Academic Research in Business and Social Sciences, Vol. 1, pp 79-101.

5. Aslan, Sebnem \& Diken, Ahmet \& Sendogdu, A. Aslan, (2011) "Investigation of the Effects of Strategic Leadership on Strategic Change and Innovativeness of SMEs in a Perceived Environmental Uncertainity”, Procedia Social and Behavioral Sciences, Vol. 24, pp 627-642.

6. B. Avey, James, E. Palanski, Michael \& O. Walumbwa Fred, (2011) "When Leadership Goes Unnoticed: The Moderating Role of Followers Self-Esteem on the Relationship between Ethical Leadership and Follower Behavior", Journal of Business Ethics, Vol. 98, pp 573-582.

7. Bambale, Abdu Ja'afaru \& Mohd Shamsudin, Faridahwati \& A/L Subramaniam, Chandrakanatan, (2011) "Simulating Organizational Citizenship Behavior (OCB) Research for Theory 
International Journal of Managing Public Sector Information and Communication Technologies (IJMPICT) Vol. 4, No. 1, March 2013

Development: Exploration of Leadership Paradigms", International Journal of Academic Research in Business and Social Sciences, Vol. 1, pp 48-69.

8. Balkundi, Prasad \& Kilduff, Martin, (2006) "The ties that lead: A social network approach to leadership", The Leadership Quarterly, Vol. 17, pp 419-439.

9. Barling, Julin \& Christie, Amy \& Turner Nick, Pseudo, (2008) "Transformational Leadership: Towards the Development and Test of a Model”, Journal of Business Ethics, Vol. 81, pp 851-861.

10. Bin, Zahari \& Ali Shurbagi, Adel Mohamed, (2012) "The Effect of Organizational Culture and the Relationship between Transformational Leadership and Job Satisfaction in Petrleum Sector of Libya", International Business Research, Vol. 5, No. 9, pp 89-97.

11. Broumand, Zahra, (2003), organizational behavior management, payamnoor university press, tenth edition.

12. Cengiz Ucar, Ahmet \& Eren, Erol \& Erzengin, Esra, (2012) "Determination of the Relationship between Leadership Perceptions of Blue Collars and Organizational Outcomes by Using MLQ Analysis", Procedia-Social and Behavioral Sciences, Vol. 41, pp 196-208.

13. Dan, Anupam, (2011) "The role of leadership competencies for implementing TQM", International Journal of Quality \& Relaibility Management, Vol. 28, No. 2, pp 195-219.

14. Dion, Michel, (2012) “Are ethical theories relevant for ethical leadership?", Leadership \& Organizational Development Journal, Vol. 33, No. 1, pp 4-24.

15. E. de Vries, Reinout \& Bakker-Pieper, Angelique \& Oostenveld, Wyneke, (2012) "Leadership=Communication? The Relations of Leaders' Communication Styles with Leadership Styles, Knowledge Sharing and Leadership Outcomes", J Bus Psychol, Vol. 25, pp 367-380.

16. E. Palmer, Daniel, (2009) "Business Leadership: Three Levels of Ethical Analysis", Journal of Business Ethics, Vol. 88, pp 525-539.

17. Gazor, Hossein, (2012) "A Literature Review on Challenges of Virtual Team's Leadership", Journal of Sociological Research, Vol. 3, No. 2, pp 134-145.

18. H. Appelbaum, Steven \& St-Pierre, Normand \& Glaves, William, (1998) "Strategic organizational change: the role of leadership, learning, motivation and productivity", Management Decision, Vol. 36, No. 5, pp 289-301.

19. Hag, Sonia, (2011) "Ethics and leadership skills in the public service", Procedia Social and Behavioral Sciences, Vol. 15, pp 2792-2796.

20. Ishikawa, Jun, (2012) "Transformational leadership and gatekeeping leadership: The role of norm for maintaining consensus and shared leadership in team performance", Asia Pac J Manag, Vol. 29, pp 265-283.

21. Ivan, Loredana, (2012) "Sex role identity, nonverbal sensitivity and potential leadership style", Procedia-Social and Behavioral Sciences, Vol. 46, pp 1720-1729.

22. J. Berendt, Charles \& Christofi, Andreas \& M. Kasibhatla, Krishna \& Malindretos, John \& Maruffi, Brian, (2012) "Transformational Leadership: Lessons in Management for Today", International Business Research, Vol. 5, No. 10, pp 227-232.

23. L. Pearce, Craig \& C. Manz Charles, (2011) "Leadership Centrality and Corporate Social IrResponsibility (CSIR): The Potential Ameliorating Effect of Self and Shared Leadership on CSIR", Journal of Business Ethics, Vol. 102, pp 563-579.

24. L. Reed, Lora \& Vidaver-Cohen, Deboral \& R. Colwell Scott, (2011) "A New Scale to Measure Executive Servant Leadership: Development, Analysis, and Implications for Research", Journal of Business Ethics, Vol. 101, pp 415-434.

25. Martinez-Corcoles, Mario \& J. Gracia, Francisco \& Tomas, Ines \& M. Perro, Jose \& Schobel, Markus, (2012) "Empowering team leadership and safety performance in nuclear power plants: A multilevel approach", Safety Science, Vol. 51, pp 293-301.

26. McCann, Jack \& Holt, Roger, (2009) "Ethical Leadership and Organizations: An Analysis of Leadership in the Manufacturing Industry Based on the Perceived Leadership Integrity Scale", Journal of Business Ethics, Vol. 87, pp 211-220.

27. Mirkamali, Seyyed Mohammad \& Narenji Thani, Fatemeh \& Alami, Farnoosh, (2011) "Examining the role of transformational leadership and job satisfaction in the organizational learning of an automotive manufacturing company", Procedia-Social and Behavioral Sciences, Vol. 29, pp 139-148. 
International Journal of Managing Public Sector Information and Communication Technologies (IJMPICT) Vol. 4, No. 1, March 2013

28. Mousavi, S.H \& Heidary, Akbar \& Khamse Pour, Farzad, (2011) "The relationship between leadership styles and physical education teachers' creativity", International Journal of Academic Research in Business and Social Sciences, Vol. 1, No. 3, pp 82-84.

29. N. Nosike, Austin \& S. Oguzor, Nkasiobi, (2011) "Understanding School Leadership and Management in Contemporary Nigeria”, International Journal of Academic Research in Business and Social Sciences, Vol. 1, pp 145-154.

30. Nekoueian. Nozar, (2002) "effective leadership management”, monthly journal, No. 120.

31. Painter-Morland, Mollie, (2008) "Systemic Leadership and the Emergence of Ethical Responsiveness", Journal of Business Ethics, Vol. 82, pp 509-524.

32. Poor Ibrahimi, Sohrab \& Moradi, Muhammad, (2007) strategic leadership process, management knowledge.

33. Ros Bangun, Ir.Yuni \& R Sukarya, Fenida, (2012) "Calling for ABC (Academic-BusinessGovernment) leadership Early Identification of effective characteristics of leadership to support Triple Helix Model”, Procedia-Social and Behavioral Sciences, Vol. 52, pp 187-196.

34. Saatchi, Mahmud \& Aziz Poor Shobi, Aliakbar, (2005) "university-related effective leadership pattern design", daneshvar rafter magazine, No. 11.

35. Sen, Asim \& Eren, Erol, (2012) "Innovative Leadership for the Twenty-First Century", ProcediaSocial and Behavioral Sciences, Vol. 41, pp 1-14.

36. Slimane, Melouki, (2012) "Role and relationship between leadership and sustainable development to release social, human, and cultural dimension", Procedia-Social and Behavioral Sciences, Vol. 41, pp 92-99.

37. Soltani, Iraj \& Poorsina, Mohsen, (2005) Teamwork foundation, Arkan publication, first edition.

38. Toor, Shamas-ur-Rehman \& Ofori, George, (2009), "Ethical Leadership: Examining the Relationships with Full Range Leadership Model, Employee Outcomes, and Organizational Culture", Journal of Business Ethics, Vol. 90, pp 533-547.

39. Turkay, Selen \& Tirthali, Devayani, (2010) "Youth leadership development in virtual worlds: A case study", Procedia Social and Behavioral Sciences, Vol. 2, pp 3175-3179.

40. Tutar, Hasan \& Altinoz, Mehmet \& Cakiroglu, Demet, (2011) "Is ethical leadership and strategic leadership a dilemma? A descriptive survey", Procedia Social and Behavioral Sciences, Vol. 24, pp 1378-1388.

41. Vlok, Awie, (2012) "A leadership competency profile for innovation leaders in a science-based research and innovation organization in South Africa", Procedia-Social and Behavioral Sciences, Vol. 41, pp 209-226.

42. Voegtlin, Christian \& Patzer, Moritz \& Georg Scherer Andres, (2012) "Responsible Leadership in Global Business: A New Approach to Leadership and Its Multi-Level Outcomes”, J Bus Ethics, Vol. 105, pp1-16.

43. Xuesheng, Du \& Wenbiao, Sun, (2012) "Research on the relationship between safety leadership and safety climate in coalmines", Procedia Engineering, Vol. 45, pp 214-2199.

44. Yuan, Cheng-Kang \& Lee, Chuan-Yin, (2011) "Exploration of a construct model linking leadership types, organization culture, employees performance and leadership performance", procedia-Social and Behavioral Sciences, Vol. 25, pp 123-136.

45. Zehir, Cemal \& Erdogan, Ebru, (2011) "The Association between Organizational Silence and Ethical Leadership through Employee Performance”, Procedia Social and Behavioral Sciences, Vol. 24, pp 1389-1404.

46. Zorlu, Kursat \& Hajioglu, Umit, (2012) "The conflict issue in international business and the global leadership”, Procedia-Social and Behavioral Sciences, Vol. 41, pp 100-107. 


\section{Authors}

Ameneh Malmir received her B.S. in Public Administration from Payam Noor University, Tehran, Burojerd, Iran in 2006, and the M.S. in Public Administration from Science and Research branch, Islamic Azad University (IAU), Burojerd, Iran in 2009. She is currently a Ph.D. student in Public Administration from Science and Research branch, Management Department, Islamic Azad University (IAU), Isfahan, Iran. Her research interests include in the areas of Motivation, E-government, Productivity, Leadership, Human Resource Management.

Fariba Azizzadeh received her B.S. in Public Administration from Payam Noor University, Urmia, Iran in 2008, and the M.S. in Public Administration from Science and Research branch, Management Department, Islamic Azad University (IAU), Urmia, Iran in 2011. She is currently a Ph.D. student in Public Administration from Science and Research branch, Management Department, Islamic Azad University (IAU), Isfahan, Iran. Her research interests include in the areas of implementation of Quality Programs, Outsourcing, Performance
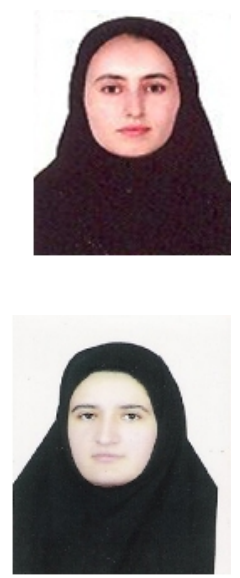